\title{
The Role Of Integration And Resilience For Improving Resource Efficiency
}

\author{
Mohammad Abdullah Shah, Muhammad Asim and Salman Manzoor
}

\begin{abstract}
The study aims to examine the impact of customer integration, internal integration, logistics collaborator integration and supply chain resilience on the resource efficiency of the supply chain firms in Karachi. Sample size included 181 responses with the help of purposive sampling, and the target population was supply chain firms of Karachi. The data was analyzed using PLS-SEM. The study found that the customer integration was significantly affecting SC resilience but negatively affecting resource efficiency. Also, internal integration was not affecting customer integration and SC resilience and resource efficiency but affecting the logistics collaborator integration. Moreover, LCI was significantly affecting customer integration, $\mathrm{SC}$ resilience and resource efficiency. Lastly, SC resilience was negatively affecting resource efficiency. The study recommends that the managers need to enhance their logistics collaborator integration as it was found to be significantly improving the customer integration, supply chain resilience and resource efficiency. Moreover, the managers need to improve their customer and internal integration as they can enhance their logistics collaboration integration and resource efficiency.
\end{abstract}

Keywords: Customer Integration, Internal Integration, Logistics Collaborator Integration, Supply Chain Resilience, Resource Efficiency.

\section{INTRODUCTION}

Due to the enhanced specializing and globalizing of the supply chain, the network of supply chain are not just becoming increasingly difficult but also suffering higher frequency and various uncertain events as in [33]. The repeated instinctiveness and manmade disasters increase the severity of challenges faced by the management of supply chain firms. For example, the earth quake that occurred in Japan in early 2016 resulted in disturbing the supply chain of the automotive industry worldwide. Hence, in last 20 years, the supply chain resilience (SCR) is becoming a problem of significant industrial and research interests as in [22]. Integration is a key viewpoint of the management of supply chain as in [10].The integration of the supply chain is found to be one of the key indicators of whether a firm can bring collaboration enhancement with their partners in supply chain, that mainly approve performance of services. Many researches have illustrated the significance of integration for the performance of a firm as in [24]. Moreover, many new researchers have found that integration can improve the resilience of a firm. However, many empirical studies have ignored the impact of integration to predict the supply chain resilience as in [39]. Lesser studies even emphasized on the problem from the viewpoint of third-party logistics providers (3PLs). 3PLs enable outsourcing of logistics services that help some or all functions of logistics needed by consumers as in [35].The
3PL is extrinsic to the client firms and repaid for their services as in [25].

3PLs do not have universally recognized sub-dimension of integration as in [11]. A very small number of researches have explained the impact on performance by integration of 3PL while integration is considered a single antecedent as in [38]. Small evidence was found empirically that emphasize on the issue if the various kinds of integration can concurrently impact supply chain resilience and 3PL performance as in [32]. The research designs and assesses the model based on concept of association among various kinds of integration, supply chain resilience as well as service performance from the 3PL aspect as in [36]. The research will be significantly beneficial to the similar researches as well as the practitioners.

The study aimed to examine the impact of various factors on the resource efficiency of a supply chain firm. This research will be beneficial for the practitioners as well as the academicians in learning about the resource efficiency of the supply chain firms in Karachi, Pakistan. The study utilized 3 antecedents of integration comprising of the customer integration, internal integration and logistics collaborator integration as the independent variables whereas the supply chain was adopted as the mediating variable of the study, while the resource efficiency was adopted as the solo dependent variable of the research model. The practitioners would be able to understand how they can improve their resource efficiency with respect to the improvement of the customer integration, internal integration, logistics collaborator integration and the supply china resilience in context to the supply chain firms of Karachi. The academicians will also be profited by this research as they will learn the effects of the integration on the resilience of the supply chain as well as how they affect the resource efficiency in the supply chain firms advancing previous studies in this context.

The sequence of the study is as follows: the first chapter discusses the background of the topic and the research problems and gap. The second chapter provides the literature of the similar studies and results. The third chapter provides the methodology that is adopted for the study. The forth chapter consists of analysis of the data with results and findings of the analysis. The fifth chapter discusses the findings of the data analysis in detail as well as implications.

\section{LITERATURE REVIEWS}

The supply chains of maritime settings are discussed at 
international level and it involves a number of different organizations as the requirement of their activities. This supply chain faces different risk factors caused by the manmade as well as the natural factors. Thus, as in [26] conducted a research to design an approach for deployment of original quality function to improve the resilience in supply chain of these maritime settings. In this study, they considered the risks factors as well as the customer requirements. The in-depth studies of the shipping lines revealed that there are top three measures for this supply chain resilience. These are the planning of contingency, maintenance and the monitoring element and lastly the relationship management in supply chain. As in [30] also investigated the relationship between the collaboration and resilience in supply chain management with the professionals. This study also revealed that collaboration with partners has significant effect on the supply chain resilience. Thus we hypothesize that:

\section{H1. Logistics collaborator integration has significant impact on supply chain resilience.}

As in [28], [29] studied the model showing association between the resilience in supply chain and the performance of firms through the survey data gathered from liner shipping companies of Taiwan. The model included reengineering, integration in the organization, agility and the organizational culture. The analysis results showed that there is a positive and direct relationship among the studied factors. Due to the increasing complexities in the working operations, the organizations have started focusing on the supply chain resilience to manage these disruptions. Thus as in [14] studied the association between the complexities in the organizations, disruptions and the overall firm performance with respect to their supply chain resilience. This study utilized the data of International manufacturing survey. This showed that disruptions within an organization increases that is mediated by the continuous performance within the organization that brings resilience in the supply chain. Thus we hypothesize that:

\section{H2. Internal integration has significant impact on supply chain resilience.}

The concept of marketing is increasing among the organizations that are generating their ability to cope with the variations in the market. The past studies have shown that the external resources are very important to gain resilience. Social capital in this regards plays a very important role. Thus as in [17] examined the effect of marketing supply chain to determine the effect of social capital on the resilience in supply chain. By using the data from 265 firms of Turkey, the analysis results showed that there is a strong relationship between the social capital supply chain resilience. Social marketing improves the integration with customers. As in [37] also revealed similar results in this context. Thus we hypothesize that:
$H 3$

\section{Customer integration has significant impact on supply chain resilience.}

The resilience in supply chain is very important for the firms to success. But there are a very limited number of studies that focused on the association between various integration types and the supply chain resilience. Thus as in [28] conducted a study to analyze the proposed model for this association. They conducted a survey with 161 firms of 3PL based in Taiwan. Through partial least square method, this study showed that logistics collaborator integration has significant impact on the efficient usage of resources by the firms that improves organizational performance. As in [9] conducted another study and provided similar findings. Thus we hypothesize that:

H4. Logistics collaborator integration has significant impact on resource efficiency.

The concept of internal integration with respect to supply chain resilience and ultimately with the usage of resource by the firms is increasing among the organizations. However there is a lacking in research conducted in this field. Thus as in [9] conducted a qualitative study that was followed by a quantitative survey method. Through partial least square analysis, it was found that integration of the firms have positive and significant impact on the organizational operations and ultimately enables a firm to utilize available resources efficiently. As in [14] also did a research in this case and found similar results. Thus we hypothesize that:

\section{H5. Internal integration has significant impact on resource efficiency.}

As in [27] aimed to examine the effect of different major dimensions of the supply chain resilience and the efficiency of resources of the firms. With the help of a survey data collected from 77 organizations, this study designed a model for the organizational resources and its performance. The analysis results showed that the organizational resources' efficiency is positively affected by its integrations with the customers. A study by as in [9] also has same findings. Thus we hypothesize that:

\section{H6. Customer integration has significant impact on resource efficiency.}

As the globalization and specialization have increased, the supply networks of the companies have become more complex and also it is facing certain events time to time that are unproductive. There are very studies that have focused on the integration collaboration in logistics and its impact on the other organizational integrations including the customer based integration. Thus as in [28] conducted a study on Taiwanese 3PLs and it was identified that there is a strong relationship between the logistics collaborator integration and the customer integration. Similar results had been identified by as in [9]. Thus we hypothesize that: 

impact on customer integration.

Integration plays a very important role in the organizations as it helps improving the collaboration between the internal as well as the external management of the organization. A study conducted by as in [28], [29] showed that internal integration of the organizations play a very important role to develop collaboration with other partners. As in [30] also found that the visibility in the supply chain partnership increases due to the internal strong integration in the supply china. Thus we hypothesize that:

\section{H8. Internal integration has significant impact on customer integration.}

Internal integration has significant impact on logistics collaborator integration.

As the supply chain is getting complex time to time due to the effects of globalization, this complexity is managed through agile and lean strategies for the improvement in supply chain flexibility and the efficiency. Resilience is needed in supply chain to avoid any disturbances. However a very limited research has been conducted on the association between supply chain resilience and the resources efficiency of firms as in [31]. Thus as in [34] conducted a study in this regard and identified that the quality of information and trust are the major factors for supply chain resilience and ultimately it was found that there is a strong relationship between this supply chain resilience and the resource efficiency of the organizations. Thus we hypothesize that:

\section{H10. Supply chain resilience has significant impact on} resource efficiency.

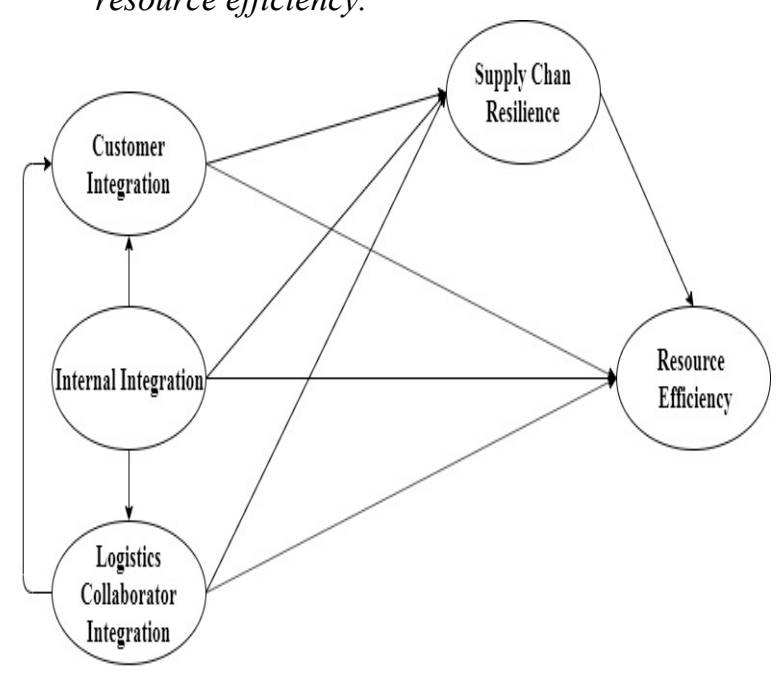

\section{METHODOLOGY}

The primary role of positivistic philosophy means that the positive knowledge is made and based on the phenomena of natural occurrence and their properties. Similarly, it was stated by as in [13] that positivistic can be defined as the inclusion of facts and details that are ought to be true and it does not have any type of intangible and false deductions. Also, one of the important aspects of this philosophy is that the knowledge development consists of pure study and examination in it as in [23].

Furthermore, the two research approaches that can be used for collecting that data is basically divided into two types including quantitative and qualitative. So, quantitative approach refers to the process in which the researcher collect data based on numeric values and statistical based data which then can be examined via statistical techniques as in [1]. Moreover, another research method that is research design defines the relationship among the variables. So, the research design is divided into several types but the highly essential one is correlational design. This research design is based on examining the relationship between the variables and defines what relation is occurring and in which manner as in [2]. Therefore, in the presence of these advantages this study has selected quantitative approach and correlation design. The rational was that it helped researcher in getting accuracy regarding the results of the study. Similarly, quantitative approach was selected because it could provide enhance summary of results in order to generalize the result as in [3]. On the other hand, the correlation design was selected for getting high strength and extent of an occurring relationship so that future researchers could more narrow the results and enhance the understanding as in [4].

However, another important process in conducting a research is collecting data and it can be achieve via various techniques. So, five-point Likert scale is a method which refers that the data collection will be done using questionnaires as in [12]. Similarly, the main objective of this scale is to provide a different or range in the length for respondents so that they could easily display the responses to research questions. Additionally, these respondents have to be chosen via one of sampling techniques. The important and essential sampling technique is purposive in which the respondents are to be selected that are quite closely related towards the research problem as in [5]. Hence, this study has chosen five-point Likert scale and purposive sampling because it helped in getting the data via using statistical means from having high variety in length of question as in [6]. Similarly, the purposive sampling was selected just because it helped the researcher to collect data from the specifically related people of the target population and gave quite useful results and findings regarding the research questions as in [7]. The study has collected total 181 responses from the manufacturing firm of Karachi, Pakistan based on the estimated minimum sample size using N10 formula as in [20].

At last, this study has aimed to use PLS-SEM analysis technique and the rational for selecting this was that it could highly help in analyzing the statistical based data and such models that were complex one as in [8]. However, in the current technique there are two models present that were measurement and structural model. Similarly, it also could help in analyzing the validity and the reliability regarding the variables of the study as in [15]. 


\section{RESULTS AND FINDINGS}

The demographic profile of the 181 respondents has been provided in the following table 1 .

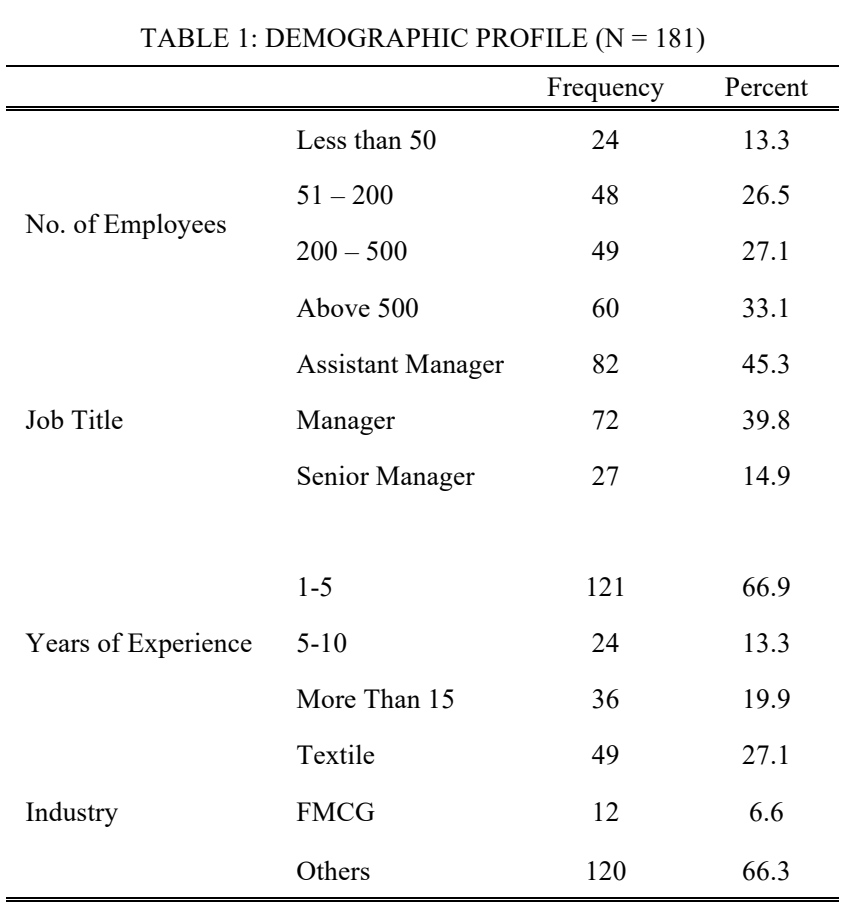

\section{A. Measurement Model}

Following section of the measurement model deals with the estimation and results of crossloadings, convergent validity and discriminant validity. These estimations were based on PLS algorithm using SmartPLS version 3.2.8.

TABLE 2: CROSS LOADINGS

\begin{tabular}{lccccc}
\hline \hline & $\begin{array}{c}\text { Custo } \\
\text { mer } \\
\text { Integr } \\
\text { ation }\end{array}$ & $\begin{array}{c}\text { Internal } \\
\text { Integrati } \\
\text { on }\end{array}$ & $\begin{array}{c}\text { Logistics } \\
\text { Collaborator } \\
\text { Integration }\end{array}$ & $\begin{array}{c}\text { Resource } \\
\text { Efficiency }\end{array}$ & $\begin{array}{c}\text { SC } \\
\text { Resilience }\end{array}$ \\
\hline ER2 & 0.081 & 0.262 & 0.443 & 0.740 & 0.101 \\
ER5 & 0.651 & 0.398 & 0.585 & 0.853 & 0.317 \\
ER6 & 0.477 & 0.130 & 0.299 & 0.907 & -0.170 \\
IC3 & 0.871 & 0.223 & 0.397 & 0.396 & 0.205 \\
IC4 & 0.945 & 0.221 & 0.315 & 0.532 & -0.004 \\
IC7 & 0.952 & 0.448 & 0.577 & 0.514 & 0.213 \\
II5 & 0.088 & 0.901 & 0.623 & 0.217 & 0.503 \\
II6 & 0.494 & 0.934 & 0.642 & 0.351 & 0.468 \\
LCI2 & 0.512 & 0.724 & 0.937 & 0.430 & 0.808 \\
LCI5 & 0.325 & 0.478 & 0.861 & 0.551 & 0.401 \\
SCR2 & 0.366 & 0.189 & 0.615 & 0.234 & 0.784 \\
SCR3 & -0.084 & 0.637 & 0.539 & -0.051 & 0.834 \\
\hline \hline
\end{tabular}

It was stated by as in [19] that factor loadings should be atleast 0.70 or higher for adequate construct development. Herein, above table showed that all the bold values have higher loading than 0.70 and in contrast to all other constructs in their respective horizontal settings. Thereby, construct validity using cross loadings has been achieved.

\begin{tabular}{lcc}
\multicolumn{3}{c}{ TABLE 3: CONVERGENT VALIDITY } \\
\hline \hline Construct & $\begin{array}{c}\text { Composite } \\
\text { Reliability }\end{array}$ & $\begin{array}{c}\text { Average Variance } \\
\text { Extracted (AVE) }\end{array}$ \\
\hline Customer Integration & 0.946 & 0.853 \\
Internal Integration & 0.914 & 0.842 \\
Logistics Collaborator Integration & 0.894 & 0.809 \\
Resource Efficiency & 0.874 & 0.699 \\
Supply Chain Resilience & 0.792 & 0.655 \\
\hline \hline
\end{tabular}

AVE should be greater than 0.50 and composite reliability should be atleast 70percent for an adequate degree of convergence among measures as in [18], [19]. Therefore, it has been evidently proven that current study has achieved convergent validity. Following table provides result of discriminant validity using as in [16] criterion.

TABLE 4: FORNELL AND LARCKER (1981) CRITERION

\begin{tabular}{|c|c|c|c|c|c|}
\hline & CI & II & LCI & $\mathrm{RE}$ & SCR \\
\hline $\begin{array}{l}\text { Customer } \\
\text { Integration }\end{array}$ & 0.923 & & & & \\
\hline $\begin{array}{l}\text { Internal Integration } \\
\text { Logistics }\end{array}$ & 0.338 & 0.918 & & & \\
\hline $\begin{array}{l}\text { Collaborator } \\
\text { Integration }\end{array}$ & 0.481 & 0.689 & 0.900 & & \\
\hline Resource Efficiency & 0.523 & 0.316 & 0.529 & 0.836 & \\
\hline $\begin{array}{ll}\text { Supply } & \text { Chain } \\
\text { Resilience } & \\
\end{array}$ & 0.157 & 0.526 & 0.709 & 0.103 & 0.810 \\
\hline
\end{tabular}

The squared-root of AVE for particular latent constructs should be greater than its corresponding other constructs to achieve discriminant validity. This method of discriminant validity has been popularly recognized as in [16] criterion. In the above table, it was shown that all latent constructs have distinctive role in the model and thus, discriminant validity has been achieved.

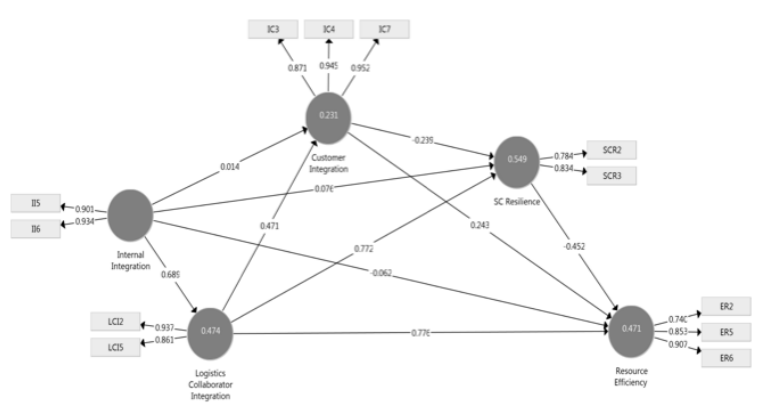




\section{B. Structural Model}

Following section of structural model deals with the hypothesis-testing using path analysis. The estimation of path analysis was based on PLS bootstrapping at 5000 subsamples and 90 percent confidence interval using Smart PLS version 3.2.8.

\section{TABLE 5: HYPOTHESIS-TESTING USING PATH ANALYSIS}

\begin{tabular}{llccc}
\hline & & Est. & Prob. & Decision \\
\hline $\begin{array}{l}\text { H1.LCI has significant impact on } \\
\text { SCR. }\end{array}$ & 0.772 & 0.000 & Accepted \\
$\begin{array}{l}\text { H2.Internal integration has significant } \\
\text { impact on SCR. }\end{array}$ & 0.076 & 0.687 & Rejected \\
$\begin{array}{l}\text { H3.Customer integration has } \\
\text { significant impact on SCR. }\end{array}$ & -0.239 & 0.062 & Accepted \\
$\begin{array}{l}\text { H4.LCI has significant impact on } \\
\text { resource efficiency. }\end{array}$ & 0.776 & 0.000 & Accepted \\
$\begin{array}{l}\text { H5.Internal integration has significant } \\
\text { impact on resource efficiency. }\end{array}$ & -0.062 & 0.465 & Rejected \\
$\begin{array}{l}\text { H6.Customer integration has } \\
\text { significant impact on resource }\end{array}$ & 0.243 & 0.003 & Accepted \\
$\begin{array}{l}\text { ffficiency. } \\
\text { H7.LCI has significant impact on } \\
\text { customer integration. }\end{array}$ & 0.471 & 0.000 & Accepted \\
$\begin{array}{l}\text { H8.Internal integration has significant } \\
\text { impact on customer integration. }\end{array}$ & 0.014 & 0.861 & Rejected \\
$\begin{array}{l}\text { H9.Internal integration has significant } \\
\text { impact on LCI. }\end{array}$ & 0.689 & 0.000 & Accepted \\
$\begin{array}{l}\text { H10.SCR has significant impact on } \\
\text { resource efficiency. }\end{array}$ & -0.452 & 0.000 & Accepted \\
\hline \hline
\end{tabular}

Above table showed that $\mathrm{H} 1$ postulating logistics collaborator integration (LCI) has significant effect on supply chain resilience (SCR) has been accepted

while the relationship between LCI and SCR was also found positive. Moreover, $\mathrm{H} 2$ was rejected manifesting that internal integration does not have any implications for supply chain resilience. $\mathrm{H} 3$ has been accepted postulating significant relationship between customer integration and SCR while it was found negative due to the fact that increasing demand of the customer may causes firms' resilience to suffer in some manner. In addition, H4 has been accepted positing that LCI may help to improve SCR in the manufacturing firms of Karachi, Pakistan; whereas H5 has been rejecting postulating that internal integration may not even improve resilience but somehow deteriorates the resource efficiency of manufacturing firms. However, customer integration helps to improve resource efficiency accepting $\mathrm{H} 6$. The results further showed that $\mathrm{H} 7$ has been accepted while $\mathrm{H} 8$ has been rejected at 95 percent confidence interval. $\mathrm{H} 9$ has been accepted but $\mathrm{H} 10$ has been accepted with negative relationship positing that increasing supply chain resilience may deteriorate the resource efficiency of the manufacturing firms of Karachi, Pakistan.

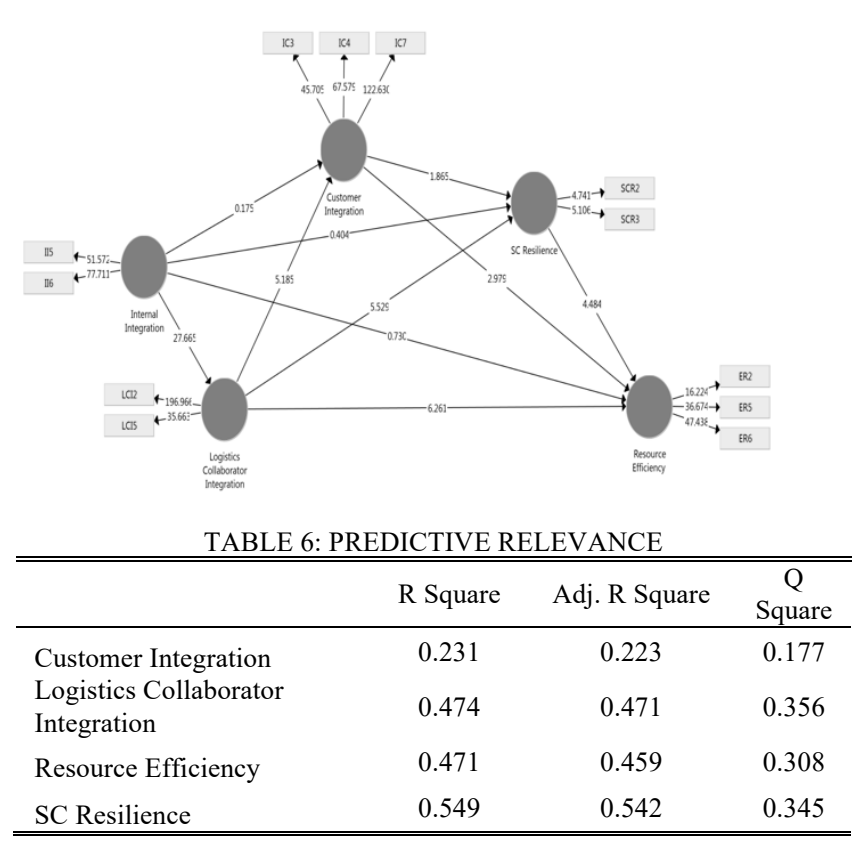

Above table for the predictive relevance showed that all endogenous latent constructs have achieved weak to moderate ( 0.25 to 0.50$)$ predictability power represented by R-Square as in [20], whereas Q-Square statistics showed that latent constructs have weak to moderate $(0.15$ to 0.35$)$ predictive relevance as in [21].

\section{CONCLUSION AND RECOMMENDATIONS}

The research has found a significantly positive relationship between customer integration with resource efficiency and significant negative relationship with SC resilience; internal integration has a insignificant positive relationship with customer integration, SC resilience, whereas insignificant negative relationship with resource efficiency. Internal integration has a significant positive relationship with logistic collaborator integration only. Logistics collaborator integration has a significant positive relation with customer integration, resource efficiency, SC resilience. Also, SC resilience has significant positive relationship with resource efficiency.

So, the present study concluded that consumer integration helps improve the efficiency of the company because the customer knows where to go and who to speak to in order to get the job done. In essence, every person has power over his or her company resources. Customer integration has a negative impact on the SC resilience because it creates the disturbance in the supply chain process but somehow also helps in increasing their capacity to recover quickly and respond back aggressively.

Furthermore, internal integration is the most important cost-containment contributor while the best strategy for achieving reliable performance in the supply chain is integration with the supplier. Customer availability of electronic ordering systems is an important cost- 
containment strategy. Fast and easy buying is the best performance delivery technique for the consumer.

Additionally, A robust supply chain is a competitive advantage, decreases consumer perception of perceived risks and pushes businesses to risk-resilient growth from simplistic risk management. Companies focused on supply chain stability are responding cohesively to adverse events quicker than rivalry to gain market share and outperform.

Moreover, it also concluded that more quickly the company resists Interruption and regeneration of operational capacity after interruption the more it will indicate an increase in their resource efficiency. Lastly, Collaborative Distribution addresses the need to evolve in order to improve service to end customers and the rest of the supply chain: manufacturers, distributors, distribution providers and quality auditors. Therefore, it eventually improves customer and internal integration, and $\mathrm{SC}$ resilience.

There are some of the recommendations present in this current study. Firstly, quality is the key to getting loyalty from the consumer. So it is recommended to the managers that Consistent and high-quality products, fast response times and open communication platforms lead to better customer experiences and potential sales growth of over 300 percent. This indicates that customers know they are relevant.

Secondly, Organizations may collect data to help serve their needs as consumers interact with products and services. Surveys, marketing promotions and media crosspromotional events can help fine-tune the targeting and segmentation of consumers. As a campaign becomes more concentrated, the more customers feel linked to the brand.

Furthermore, it is recommended If there is cooperation between two companies, it would help to reduce the cost of holding inventories and at the same time increase consumer loyalty by executing on schedule. If any supply chain is redundant, it would be helpful during peak demand and increase recovery during shutdown due to circumstances such as power cut, flood, and earthquake. If a supply chain is adaptive, the output lead time and total cost would be high.

Moreover, Supply chain often faces interruption due to a cyber-attack or entry to a restricted area due to its data leak. Through providing security in any organization, this issue can be solved.

Additionally, an intranet also features a robust employee communication platform with easy-to-use collaboration and conversation tools, including tools that streamline daily business processes. In a judgment-free environment, it empowers employees to connect and share ideas. It will help the organization in achieving internal integration.

Few of the recommendations present in this study are: Firstly, the sample size of the current study is limited so the potential researcher can study this subject on a larger sample size. Secondly, the target participants are the employee of Karachi only; so, other Pakistani cities or other DOI: http://dx.doi.org/10.24018/ejbmr.2020.5.1.183 countries can also be targeted for future research in order to get a broader picture on this subject. Thirdly, future researcher can use longitudinal research approach as well.

\section{REFERENCES}

[1] Araoye, M.O. Research methodology with statistics for health and social sciences. Ilorin: Nathadex Publisher, 115(9), year 2003.

[2] Asika, N. Research methodology in the behavioural sciences. Lagos: Longman Nigeria Plc, 90-96, year 1991.

[3] Babbie, E.R. Survey research methods: Wadsworth, year 1973.

[4] Babbie, E.R. The practice of social research (Vol. 112): Wadsworth publishing company Belmont, CA, year 1998.

[5] Blessing, L.T., \& Chakrabarti, A. Drm, a design research methodology: Springer Science \& Business Media, year 2009.

[6] Brink, H., Van der Walt, C., \& Van Rensburg, G. Fundamentals of research methodology for health care professionals: Juta and Company Ltd, year 2006.

[7] Burns, R.B. Introduction to research methods, year 2000.

[8] Chin, W.W., Thatcher, J.B., Wright, R.T., \& Steel, D. Controlling for common method variance in pls analysis: The measured latent marker variable approach New perspectives in partial least squares and related methods (pp. 231-239): Springer, year 2013.

[9] Chowdhury, M.M.H., \& Quaddus, M. Supply chain resilience: Conceptualization and scale development using dynamic capability theory. International Journal of Production Economics, 188, 185-204, year 2017.

[10] Christopher, M., Lowson, R., \& Peck, H. Creating agile supply chains in the fashion industry. International Journal of Retail \& Distribution Management, 32(8), 367-376, year 2004.

[11] Christopher, M., \& Peck, H. Building the resilient supply chain. The international journal of logistics management, 15(2), 1-14, year 2004.

[12] Churchill, T.B., \& Arthur, J.M. Measuring spider richness: Effects of different sampling methods and spatial and temporal scales. Journal of Insect Conservation, 3(4), 287-295, year 1999.

[13] Compte, A. The positive philosophy of auguste compte: London, UK: Chapman, year 1854.

[14] Donadoni, M., Caniato, F., \& Cagliano, R. Linking product complexity, disruption and performance: The moderating role of supply chain resilience. Paper presented at the Supply Chain Forum: An International Journal, year 2018.

[15] Fornell, C. A comparative analysis of two structural equation models: Lisrel and pls applied to market data, year 1981.

[16] Fornell, C., \& Larcker, D.F. Structural equation models with unobservable variables and measurement error: Algebra and statistics. Journal of marketing research, 382-388, year 1981.

[17] Gölgeci, I., \& Kuivalainen, O. Does social capital matter for supply chain resilience? The role of absorptive capacity and marketingsupply chain management alignment. Industrial Marketing Management, year 2019.

[18] Hair, J.F., Black, W.C., Babin, B.J., Anderson, R.E., \& Tatham, R.L. Multivariate data analysis: Pearson, year 2010.

[19] Hair, J.F., Hult, G.T.M., Ringle, C., \& Sarstedt, M. A primer on partial least squares structural equation modeling (pls-sem): Sage Publications, year 2016

[20] Hair, J.F., Ringle, C.M., \& Sarstedt, M. Pls-sem: Indeed a silver bullet. Journal of Marketing theory and Practice, 19(2), 139-152, year 2011.

[21] Hair, J.F., Ringle, C.M., \& Sarstedt, M. Partial least squares structural equation modeling: Rigorous applications, better results and higher acceptance. Long range planning, 46(1-2), 1-12, year 2013

[22] Hohenstein, N.-O., Feisel, E., Hartmann, E., \& Giunipero, L. Research on the phenomenon of supply chain resilience: A systematic review and paths for further investigation. International Journal of Physical Distribution \& Logistics Management, 45(1/2), 90-117, year 2015.

[23] Hughes, J.A., \& Sharrock, W.W. The philosophy of social research: Routledge, year 2016

[24] Huo, B. The impact of supply chain integration on company performance: An organizational capability perspective. Supply Chain Management: An International Journal, 17(6), 596-610, year 2012.

[25] Jüttner, U., \& Maklan, S. Supply chain resilience in the global financial crisis: An empirical study. Supply Chain Management: An International Journal, 16(4), 246-259, year 2011. 
[26] Lam, J.S.L., \& Bai, X. A quality function deployment approach to improve maritime supply chain resilience. Transportation Research Part E: Logistics and Transportation Review, 92, 16-27, year 2016.

[27] Li, X., Wu, Q., Holsapple, C.W., \& Goldsby, T. An empirical examination of firm financial performance along dimensions of supply chain resilience. Management Research Review, 40(3), 254269, year 2017.

[28] Liu, C.-L., \& Lee, M.-Y. Integration, supply chain resilience, and service performance in third-party logistics providers. The International Journal of Logistics Management, 29(1), 5-21, year 2018.

[29] Liu, C.-L., Shang, K.-C., Lirn, T.-C., Lai, K.-H., \& Lun, Y.V. Supply chain resilience, firm performance, and management policies in the liner shipping industry. Transportation Research Part A: Policy and Practice, 110, 202-219, year 2018.

[30] Mandal, S., Sarathy, R., Korasiga, V.R., Bhattacharya, S., \& Dastidar, S.G. Achieving supply chain resilience: The contribution of logistics and supply chain capabilities. International Journal of Disaster Resilience in the Built Environment, 7(5), 544-562, year 2016.

[31] Masson, R., Iosif, L., MacKerron, G., \& Fernie, J. Managing complexity in agile global fashion industry supply chains. The International Journal of Logistics Management, 18(2), 238-254, year 2007.

[32] Mentzer, J.T., Flint, D.J., \& Hult, G.T.M. Logistics service quality as a segment-customized process. Journal of marketing, 65(4), 82-104, year 2001.

[33] Moslemi, A., Hilmola, O.-P., \& Vilko, J. Risks in emerging markets: Logistics services in the mediterranean region. Maritime Business Review, 1(3), 253-272, year 2016.

[34] Nikookar, E., Nagalingam, S., \& Soosay, C. (2015). The role of visibility in supply chain resilience: A resource-based approach. Paper presented at the 29th Annual Conference of the Australian \& New Zealand Academy of Management.

[35] Virum, H. Third party logistics. Report, The Research Center, Norwegian School of Management, Oslo, year 1993.

[36] Wieland, A., \& Marcus Wallenburg, C. The influence of relational competencies on supply chain resilience: A relational view. International Journal of Physical Distribution \& Logistics Management, 43(4), 300-320, year 2013.

[37] Yu, W., Jacobs, M.A., Chavez, R., \& Yang, J. Dynamism, disruption orientation, and resilience in the supply chain and the impacts on financial performance: A dynamic capabilities perspective. International Journal of Production Economics, 218, 352-362, year 2019.

[38] Zhang, G., Shang, J., \& Li, W. Collaborative production planning of supply chain under price and demand uncertainty. European Journal of Operational Research, 215(3), 590-603, year 2011.

[39] Zhang, M., \& Huo, B. The impact of dependence and trust on supply chain integration. International Journal of Physical Distribution \& Logistics Management, 43(7), 544-563, year 2013. 